\title{
Oxygen semipermeability of erbia-stabilized bismuth oxide
}

\author{
H.J.M. Bouwmeester, H. Kruıdhof, A.J. Burggraaf and P.J. Gellıngs

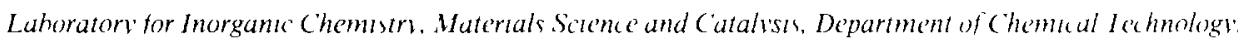 \\ Lniverstr of Twente, PO Box 21?. 500 4E Enschede. The Netherlands
}

\begin{abstract}
The isothermal permeability of oxygen through sintered dense disks of bismuth oxide stabilized w'th 25 mol\% erbia (BE25) has been studied at $610-810^{\circ} \mathrm{C}$ and oxygen pressures of $00001-1$ atm It is concluded that the permeating flux is rate limited both by solid state diffusion of electron holes and by the surface exchange reaction From the results the p-type electronic conduct1vity of BE25 and the surface oxygen exchange rate have been evaluated The value obtaned for the latter shows excellent agreement with that obtained from ${ }^{18} \mathrm{O}-{ }^{16} \mathrm{O}$ isotope exchange reported previously Using gold point electrodes it is demonstrated that the oxygen semipermeability flux in case of partial rate control by surface oxygen exchange leads to deviations from Nernst behav 1our, though oxygen permeation measurements reveal that under the applied conditions BE25 remains a solid electrolyte with an tonic transference number close to unity
\end{abstract}

\section{Introduction}

4 promising use of ceramic mixed conducting oxides is as membranes designed to separate oxygen from air or other gases. At elevated temperatures these membranes are semipermeable to oxygen while being impervious to other gaseous components. The transport of oxygen, arising from thermal dissociation of chemisorbed molecular species on the oxidic surface, is possible by the joint diffusion of oxygen anions, or vacancies, and electronic species through the membrane under the driving force of a gradient in oxygen chemical potential [2] The permeating flux can be used advantageously in facilitating many reactions of interest either by extracting or by supplying oxygen in a partial pressure gradient without the need for external voltages. Examples include, e g. the dissociation of steam for the production of hydrogen [3.4] and the oxidative dehydrodımerization of propene [5].

The existence of a nonvanishing electronic conduction in the ionic domain of solid electrolytes such as $\mathrm{ZrO}_{2}$ doped with $\mathrm{CaO}$ or $\mathrm{Y}_{2} \mathrm{O}_{3}$ and the accompanyıng semipermeability flux can be detrimental in high-temperature oxygen gauges [6,7]. The problems due to oxygen semipermeability are most serious in measurements of $P_{\mathrm{O}}$ : in unbuffered gas mix- tures at low oxygen partial pressures A further limitation is that the electrode/electrolyte interface may become polarized due to a limited exchange rate yielding errors far larger than predicted purely on the basis of departure of the ionic transference number from unity

The aim of this study is to obtain more insight in the mechanism of oxygen permeation, enabling the proper selection of candidate materials for application in, for example, high temperature oxygen gauges and as (catalyst) membranes Erbia-stabilized bismuth oxide with molar composition $\left(\mathrm{B}_{2} \mathrm{O}\right)_{0{ }_{75}}\left(\mathrm{Er}_{2} \mathrm{O}\right)_{025}(\mathrm{BE} 25)$, a solid electrolyte exhibiting one of the highest reported ionic conductivities, was chosen since this material has been well characterized in a number of other studies performed in this laboratory [8-15]

\section{Theory}

The schematics of a membrane semipermeable to oxygen is shown in fig 1 . By applying a $P_{O_{2}}$ differential, oxygen is driven across the membrane from the high $P_{\mathrm{O}_{2}}$ to the low $P_{\mathrm{O}_{2}}$ side The oxygen flux is facilitated by the joint diffusion of oxygen anions and clectrons, or associated lattıce defects, which com- 


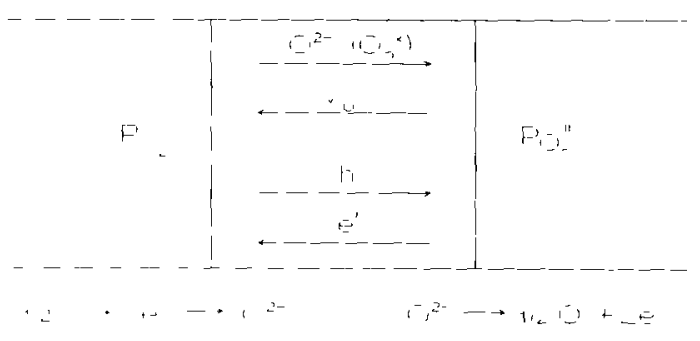

Fig 1 Representation of relevant fluxes through a ceramic membrane upon applying a $P_{()_{2}}$ differentıal, $P_{\mathrm{O}_{2}}^{\prime}>P_{\mathrm{O}_{2}}^{\prime \prime}$ The notation used for defects is from ref [1]

pensate each other electrically as required by local charge neutrality. The slowest moving species determines the net rate of oxygen permeation. In the materials being dealt with here metal ion diffusion can be left out of consideration.

In actual application one is interested in the magnitude of the permeating flux as a function of the partial pressure applied to the two sides of the membrane Wagner's theory of oxide film growth on metals provides a means by which the flux across the membrane can be related to measurable electrical parameters [2]

$J_{()_{2}}=\frac{R T}{4 F^{2} L} \int_{u_{()_{2}}^{\prime \prime}}^{\left.a_{\prime \prime}^{\prime}\right)_{2}} t_{\text {ion }} t_{\mathrm{el}} \sigma_{\mathrm{total}} d\left[\ln a_{()_{2}}\right]$.

In this equation $t_{\mathrm{son}}$ and $t_{\mathrm{el}}$ are the fractions (transference numbers) of the total conductivity, $\sigma_{\text {total }}$ $\left(=\sigma_{\mathrm{nnn}}+\sigma_{\mathrm{c} 1}\right)$. which are provided by conic and electronic defects, respectively, $L$ is the thickness of the membrane and $F$ the Faraday constant. The limits of integration are the activities of molecular oxygen at the gas phase boundaries.

For oxide electrolytes such as the stabilized zirconias and bismuth oxides the ionic transference number, $t_{10 n}$ is close to unity over a wide range of temperatures and oxygen partial pressures. The partial electronic conductivity in the electrolytic domain is given by.

$\sigma_{\mathrm{e} 1}=\sigma_{r}^{0} P_{\sigma_{2}^{\prime}}^{1 / 4}+\sigma_{n}^{0} P_{\sigma_{2}}^{1 / 4}$,

reflecting the $p$ - and $n$-type contributions to the conductivity and in which $\sigma_{n}^{0}$ and $\sigma_{n}^{0}$ are the corresponding values at $1 \mathrm{~atm}$ oxygen pressure. Noting that the activity of a perfect gas is equal to its partial pressure. integration of eq. (1) yields

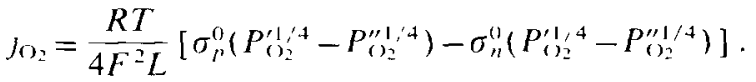

It can be seen that $f_{0}$ shows two different regimes In the $p$-type regime, at high oxygen pressures and in which n-type contributions to the electronic conductivity can be neglected, eq (3) reduces to

$\jmath_{\omega_{2}}=\frac{R T}{4 F^{2} L}\left[\sigma_{p}^{0}\left(P_{\omega_{2}}^{\prime 1 / 4}-P_{\omega_{2}}^{\prime \prime 1 / 4}\right)\right]$

while in the n-type regime, at low oxygen pressures and in which $p$-type behaviour can be neglected, it takes the form.

$J_{\mathrm{O}_{2}}=\frac{-R T}{4 F^{2} L}\left[\sigma_{n}^{(1)}\left(P_{()_{2}}^{\prime 1 / 4}-P_{()_{2}^{\prime \prime 4}}^{\prime \prime 1 / 4}\right)\right]$

Results of semıpermeability measurements with emphasis on the stabilized zirconias have been reviewed by Fouletier et al. [16] Often a higher oxygen pressure dependence is found than predicted by eqs (4a) and (4b). Dou et al. [17] were the first to invoke a surface reaction to reconcile the apparent conflict with a diffusion controlled mechanism.

A possible influence of a surface reaction comes into play whenever an oxygen potential gradient is imposed on an oxide surface and is inevitably encountered upon decreasing the sample thickness. The role of the surface on the reequilibration kinetics of nonstoichiometric oxides has been examıned by Nowotny and Wagner [18]. emphasizing the possible role of segregation of lattice components towards the surface. They arrived at the conclusion that in a large number of kinetic studies reported in literature the data from relaxation experiments appear not to be bulk controlled but actually exhibit mixed control, $1 \mathrm{e}$, the overall kınetics are determıned both by surface reactions and by bulk diffusion.

In this study it is demonstrated that the rate of oxygen permeation through BE25 is partly limited by solid state diffusion of minority electron-holes and partly by the surface exchange reactions. 


\section{Experimental}

Bismuth oxide powders containing $25 \mathrm{~mol} \%$ erbia were prepared by the coprecipitation technique usIng high purity raw materials $(99.9 \%)$. Detalls of the synthesis and preparation of these powders into machinable ceramics have been described elsewhere [9]. The relative density of the compacts was more than $99 \%$ of the theoretical value as determined from the cell parameters obtained with X-ray powder diffraction

Isothermal oxygen semipermeability measurements were performed on disk-shaped samples $(\phi=1.20 \mathrm{~cm})$ with a thıckness of 0020.0070 and $0285 \mathrm{~cm}$. respectively, which were sealed into a quartz reactor using pyrex glass rings (trade name DURAN, Schott Nederland B.V ) Prior to use these disks were polıshed on both sides, with a final polısh of $0.3 \mu \mathrm{m} \mathrm{Al}{ }_{2} \mathrm{O}_{3}$ Data were collected in the temperature range $610-810^{\circ} \mathrm{C}$ with oxygen partial pressures of $0.038-1$ atm. Measured fluxes, $J_{(2}$ ( $m o l \mathrm{~cm}^{-2} \mathrm{~s}^{-1}$ ), were normalized to the permeating surface area at the high pressure side. Strictly speaking this is somewhat arbitrary because of slight deviatıons from linear geometry due to the sealing procedure

An oxygen/nitrogen gas mixture was led over one side of the specimen. while the permeative side being flushed with high purity helium gas (UCAR Specralty Gases N.V., $\left.P_{O_{2}}=1.10 \times 10^{-4} \mathrm{~atm}\right)$ at a precisely controlled flow rate. The amount of oxygen which permeated through the specimen was determined by on-line gas chromatography (Varian model 3400 ) at the gas outlet. A molecular sieve column ( $80-100$ mesh, $6 \mathrm{ft}$. s.s.) was employed to separate oxygen and nitrogen. A schematic diagram of the apparatus is shown in fig. 2. The simultaneous measurement of nitrogen and oxygen in the sample gas permitted an easy in situ control of the gas tightness of the seal, which normally lasted the time-span of the measurements.

To see whether oxygen permeation was also controlled by the oxygen pressure at the low pressure side, the four-port valve (4PV) was shut at arbitrary time, set to zero, and the extent of oxygen permeatıon determıned by gas chromatographic analysis at regular intervals during the course of an experiment. The insıde partial pressure was allowed to vary by

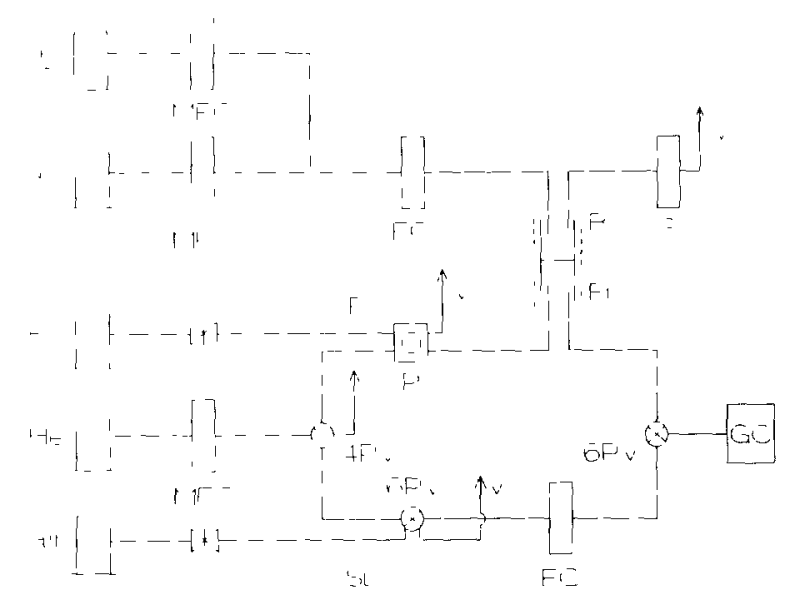

Fig 2 Diagram of apparatus (Fl) He, (Fu) furnace, (FC) flow controller, (GC) gas chromalograph, (MFC) mass flow controller, (P) membrane pump, (R) reactor, (S) oxygen sensor, (SL) sampling loop. (Ve) vent. (V) valve (4PV) four-port and (6PV) six-port valve

about two orders of magnitude.

Different gas flow rates were used. Varying these on different sides of the specimen in the range of I$30 \mathrm{ml} / \mathrm{mm}$ showed no effect on oxygen permeation. Oxygen/nitrogen gas mixtures were calıbrated using a zirconia sensor with air as reference

Computations were performed using GAMS (the acronym stands for General Algebraic Modelıng System [19]) A correction was applied to account for the decreased geometric surface at the low pressure side caused by the sealing procedure

EMF measurements were performed using gold point electrodes which were spring loaded onto the specimen surface. Air was used as reference gas The asymmetry potentral was always found to be less than $0.5 \mathrm{mV}$.

\section{Results and discussion}

\section{Oxygen sempermeabiltty measurements}

Data of oxygen permeation through BE25 were collected as a function of oxygen partial pressure and temperature In figs 3 and 4 results for specimen thicknesses 0070 and $0285 \mathrm{~cm}$ are compared. Not all data curves obtained from measurements have been plotted in these figures for reasons of clarity. 


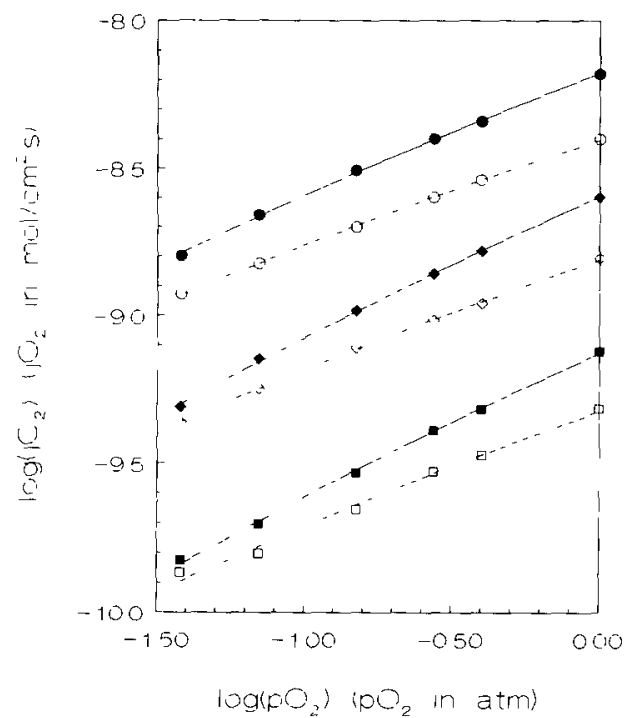

Fig 3 Pressure dependence of oxygen permeation through BE25 for two thicknesses, $0070 \mathrm{~cm}$ (full symbols) and $0285 \mathrm{~cm}$ (open symbols), at different temperatures, $650(\square, \square), 730(\bullet, \diamond)$ and $810^{\circ} \mathrm{C}(0.0)$, respectively

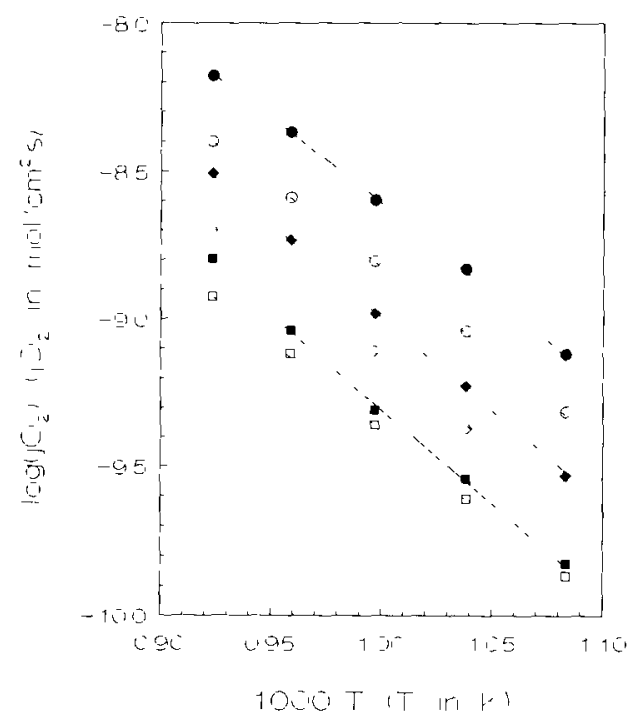

Fig 4 Temperature dependence of oxygen permeation through BE25 for two thicknesses, $0070 \mathrm{~cm}$ (full symbols) and $0285 \mathrm{~cm}$ (open symbols), at different oxygen pressures, $0038(\boldsymbol{\square}, \square$ ), $0150(\diamond, \diamond)$ and $10 \mathrm{~atm}(0,0)$, respectively

Average values of the kinetic order with respect to oxygen, $\partial \log \left(J_{\mathrm{O}_{2}}\right) / \partial \log \left(P_{\mathrm{O}_{2}}\right)$, and those of the activation energy as a function of thickness evaluated from the slopes of these curves are given in figs. 5

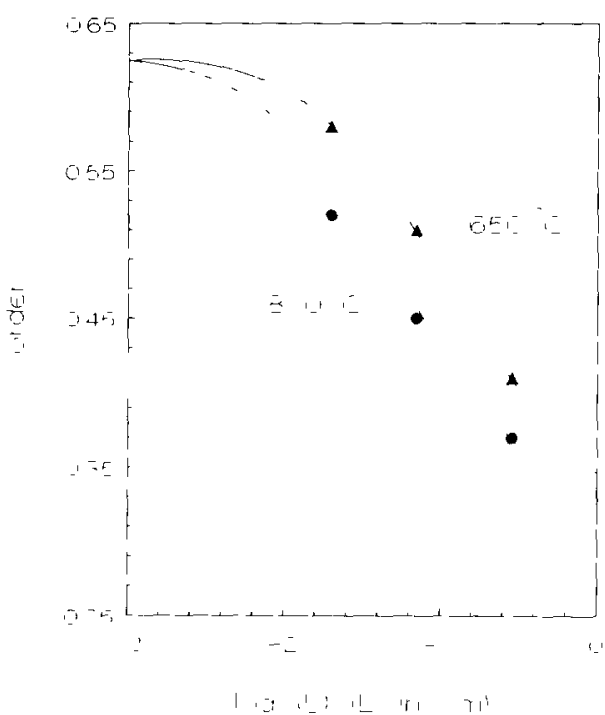

Fig 5 Kinetic order of oxygen permeation as a function of thickness, $L$, at 650 and $810^{\circ} \mathrm{C}$ Solid lines represent simulated results (see text)

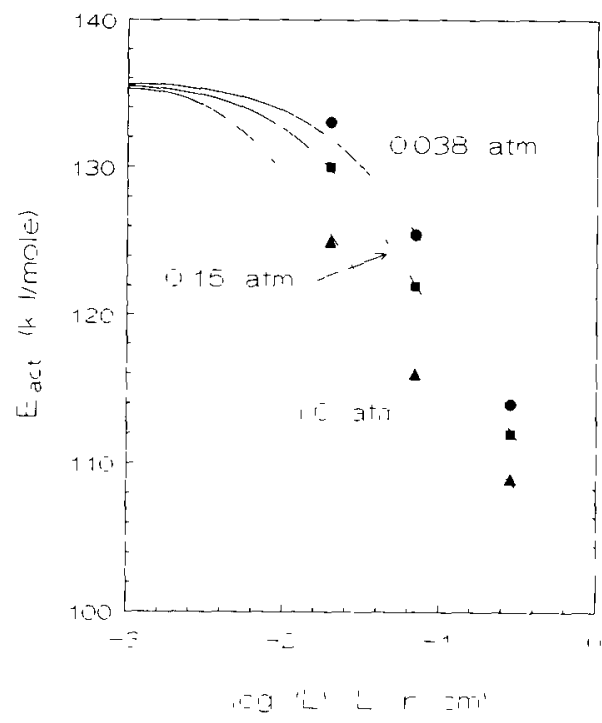

Fig 6 Activation energy of oxygen permeation as a function of thickness, $L$, at oxygen pressures of 0038,0150 and 10 atm Solıd lines represent sımulated results (see text)

and 6 , respectively. The observation that the kınetıc order and the activation energy vary with thickness is not consistent with Wagner's theory presented in section 2 but implies that permeation is limited by two or more processes. 


\section{Modeling of oxygen permeation}

Wagner's theory is based on assuming that bulk ovide properties dominate the transport behaviour. The phase boundaries are assumed to be in equilibrium with the imposed gas atmospheres The present results, however, suggest that a surface reaction $\mathrm{ex}^{-}$ erts a partial control over the permeation kinetics Both the kinetre order in $\mathrm{O}_{2}$ and the activation energy increase as thickness decreases, due to the change-over from diffusion controlled to surface controlled kinetics

To extend the theory to cases of a partial rate control by a surface reaction it is expedient to divide the membrane wall into three regions a central bulk (Wagner) zone and adjacent interfacial zones, as depicted in fig 7, emphasizing the importance of both solid state diffusion and surface exchange reactions to the extent of oxygen permeation. The avalable driving force for permeation (the gradient in oxygen chemical potential. $\left.\mu_{1}\right)_{2}$ ) is proportioned between the various zones. If the membrane is made sufficiently thick diffusion will be rate determining A mixed type of rate control is encountered upon decreasing membrane thickness Ultımately the surface reactions become rate determınıng for very thin membranes

The local chemical equilibria assumed in Wagner's theory also imply local electrical charge neutrality at every point in the membrane This assumption is not valid close to the two interface boundaries where even at equilibrium, in general. there will be a space charge region next to the surface extending into the bulk oxide The extent of the interfacial regions may therefore be of the order of the

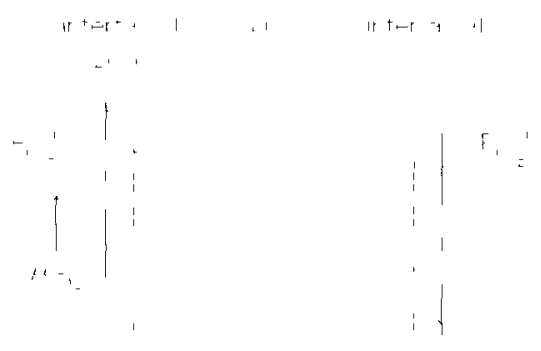

Fig 7 Schematic representation of the gradient in oxygen chemical potential $\mu_{12}$, at various zones during steady state oxygen permeation
Debye-Huckel screening length the value of which critically depends on the concentration of the present charge carriers [20].

Generally' speaking, however, the exchange of oxygen between oxide surfaces and the gas phase can be described as a multistep process involving a sequence of transfer from the gas phase to the adsorbed phase (or vice versa), surface diffusion, reactions in the adsorbed phase and incorporation in the (near-) surface layer. Several species can occur as intermediates for the reduction of oxygen, e.g. $\mathrm{O}_{2}^{-}$ads. $\mathrm{O}_{\mathrm{ad}}, \mathrm{O}_{\mathrm{dd}}^{-}, \mathrm{etc}$, leaving numerous possibilities for the rate determining step

In the absence of oxygen potential gradients oxygen exchange is characterized by a dy namic equilibrium The net rate of reaction is zero due to the balance of forward and backward reactions. The exchange flux generally found under equilibrium conditions is given by.

$J_{c,}^{\prime \prime}=\alpha P_{(1,2}^{\prime}$.

which can be determined directly using ${ }^{18} \mathrm{O}-{ }^{16} \mathrm{O}$ isotopic exchange [21] In eq (5), $r$ is the kinetic order in oxygen of the surface reaction and $\alpha$ the exchange rate at $P_{1,2}=1 \mathrm{~atm}$ normalized to unit area Because an appropriate rate equation to describe the surface oxygen exchange kinetıcs under non-equilıbrium conditions is not avalable. the net flux in this study is simply approximated by

$\mu_{12}=\alpha\left(P_{1}^{\prime}-P_{1}^{\prime}, \ldots\right)$.

where $P_{0,2}$ ox respectively $P_{0,2}$ designate the apparent (perturbed) value of the oxygen pressure at the surface respectively the one in equilibrium with the gas atmosphere Eq. (6) is likely to hold for a surface reaction proceeding sufficiently close to equilibrium. The fit results discussed below did not necessitate the use of a more sophisticated expression Note that the usual assumption that the gas phase boundaries equilibrate fast implies that $P_{\mathrm{O}_{2}}=P_{\mathrm{U}_{2}}$ or

The results of theoretical calculations are represented by the fitted curves in figs 3-6 The fluxes. (1)., were calculated numerically using the following set of equations which describe the transport of oxygen through the various sequentral zones at steadystate conditions 
$J_{\mathrm{O}_{2}}=\alpha\left(P^{\prime 5 / 8}-P_{\mathrm{ox}}^{\prime 5 / 8}\right)$

interfacial zone (high pressure side)

$J_{\mathrm{O}_{2}}=\frac{\beta}{L}\left(P_{\mathrm{ox}}^{\prime 1 / 4}-P_{\mathrm{ox}}^{\prime \prime 1 / 4}\right) \quad$ bulk oxide

$J_{\mathrm{O}_{2}}=\alpha\left(P_{\mathrm{ox}}^{\prime \prime 5 / 8}-P^{\prime \prime 5 / 8}\right)$

interfacial zone (low pressure side)

where for typographic reasons $P$ is used for $P_{\mathrm{O}_{2}}$, single and double primes refer to the high and low pressure side, respectively, and $\beta=R T \sigma_{p}^{0} / 4 F^{2}$.

The computations show both $\alpha$ and $\beta$ to be thermally activated with activation energies of $136 \pm 4$ and $99 \pm 4 \mathrm{~kJ} / \mathrm{mol}$, respectively. Arrhenıus plots are shown in fig 8 . The equations, as determined by least squares, are as follows:

$$
\begin{aligned}
\alpha & {\left[\mathrm{mol} \mathrm{cm}^{-2} \mathrm{~s}^{-1} \mathrm{~atm}^{-5 / 8}\right] } \\
& =262 \times 10^{-5} \exp \left(-136\left[\mathrm{~kJ} \mathrm{~mol}^{-1}\right] / R T\right) .
\end{aligned}
$$

and

$$
\begin{aligned}
& \beta\left[\mathrm{mol} \mathrm{cm}^{-2} \mathrm{~s}^{-1} \mathrm{~atm}^{-1 / 4}\right] \\
& \quad=171 \times 10^{-6} \exp \left(-99\left[\mathrm{~kJ} \mathrm{~mol}^{-1}\right] / R T\right)
\end{aligned}
$$

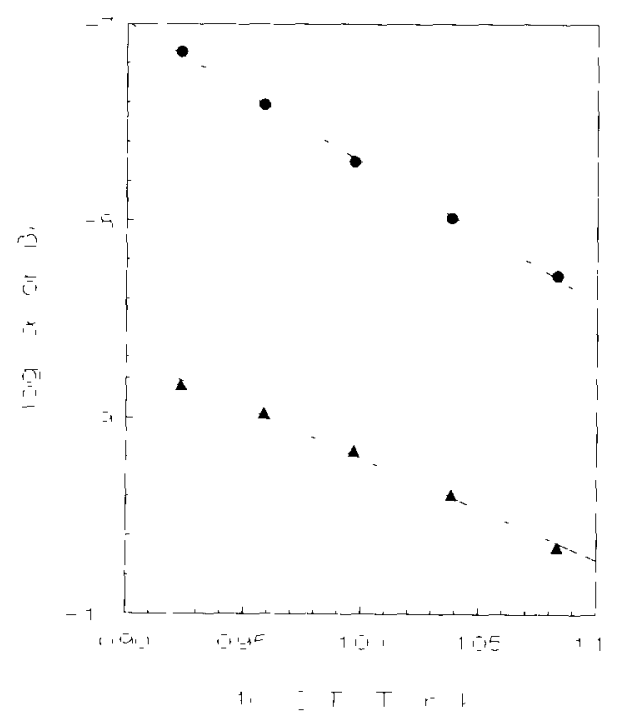

Fig 8 Temperature dependence of the surface exchange constant $\alpha(\bullet)$, and the bulk diffusion parameter, $\beta$

\section{Electronic conductivitv}

From the temperature dependence of $\beta$, the partial $p$-type electronic conductivity of BE 25 is calculated to be given by:

$$
\begin{aligned}
& \sigma_{p}\left[\Omega^{-1} \mathrm{~cm}^{-1}\right]=3.0 \times 10^{2}\left(P_{O_{2}}[\mathrm{~atm}]\right)^{1 / 4} \\
& \quad \times \exp \left(-91\left[\mathrm{~kJ} \mathrm{~mol}^{-1}\right] / R T\right)
\end{aligned}
$$

which has not been reported before in literature Calculations using the empirical equation for the ionic conductivity obtained by Verkerk et al. [8] confirm that the ionic transference number, $t_{10 n}$, is close to one. e.g. 0.992 at $650^{\circ} \mathrm{C}$ and 0.987 at $810^{\circ} \mathrm{C}$. calculated for $P_{()_{2}}=1 \mathrm{~atm}$

The oxygen exponent $1 / 4$ (eq. (4a)) is characteristic for electron-hole conductivity This also agrees with the observation that the rate of permeation does not vary significantly with the oxygen pressure at the low pressure side provided, of course, that the one at the high pressure side is kept at a substantially higher level. Takahashı et al [22] obtained an activation energy of $106 \mathrm{~kJ} / \mathrm{mol}$ and pre-exponential factor of $5.0 \times 10^{2} \Omega^{-1} \mathrm{~cm}^{-1} \mathrm{~atm}^{-1 / 4}$ for the electron-hole conductivity of bismuth oxide stabilized with $27 \mathrm{~mol} \%$ yttria (BY27) from Hebb-Wagner polarization measurements. These values are reasonably close to those observed for BE25 in this study. A distinctly higher value was found by Takahashı et al. for the activation energy of the partial electron conductivity, $E_{\mathrm{act}}=213 \mathrm{~kJ} / \mathrm{mol}$ In order to observe an $n$-type contribution to the electronic conductivity of BE25 it is necessary to extend the permeation measurements to lower oxygen pressures.

\section{Oxygen exchange rate}

The permeatıng flux will be maxımum under conditions of pure surface control. The domınating factor then is the surface exchange rate constant. $\alpha$. Its value at equilibrium can be obtained directly by experiment using oxygen isotope exchange techniques. Data of isotopic exchange on sintered dense disks of BE25 have been reported previously by Boukamp et al. $[13,14]$. They found an exchange rate with a k1netic order in $\mathrm{O}_{2}$ of 0.60 at $550^{\circ} \mathrm{C}$ and 054 at $700^{\circ} \mathrm{C}$ and a surface activation energy of $130 \pm 4 \mathrm{~kJ} / \mathrm{mol}$. Khurumchin et al. [23] reported an order of $0.7 \pm 0.1$ 
and an activation energy of $130 \mathrm{~kJ} / \mathrm{mol}$ from isotope exchange on BE20. These data agree well with the results from the present study. In the calculations the order in $\mathrm{O}_{2}$ of the surface reaction was set to $5 / 8$ although no specific mechanısm was assumed No attempt was made to refine this value as a function of temperature In fig 9. data of the surface oxygen exchange rate (normalized to air) obtained by Boukamp et al. [13,14] are compared with our values The close correspondence supports the described model for oxygen permeation

Besides ${ }^{18} \mathrm{O}_{2}$ and ${ }^{16} \mathrm{O}_{2},{ }^{16} \mathrm{O}^{18} \mathrm{O}$ molecules will also be formed in the gas phase during isotopic exchange. From the time dependence of the concentrations of each of these species Boukamp et al $[13,14]$ concluded that the dissociative adsorption is the rate limiting step in the exchange process on BE25 powders. The detailed mechanism is, however, not yet understood.

The value measured for the direct (heterogeneous) exchange rate, $j_{e_{x}}^{0}$ (eq (5)), relates to the electrochemical accessible exchange current density, $l_{0}$. which expresses the balanced Faraday actıvity at equilibrium, assuming no activation of applied electrodes. That is, the assumption is made that the clectrodes are acting as current collectors and do not in-

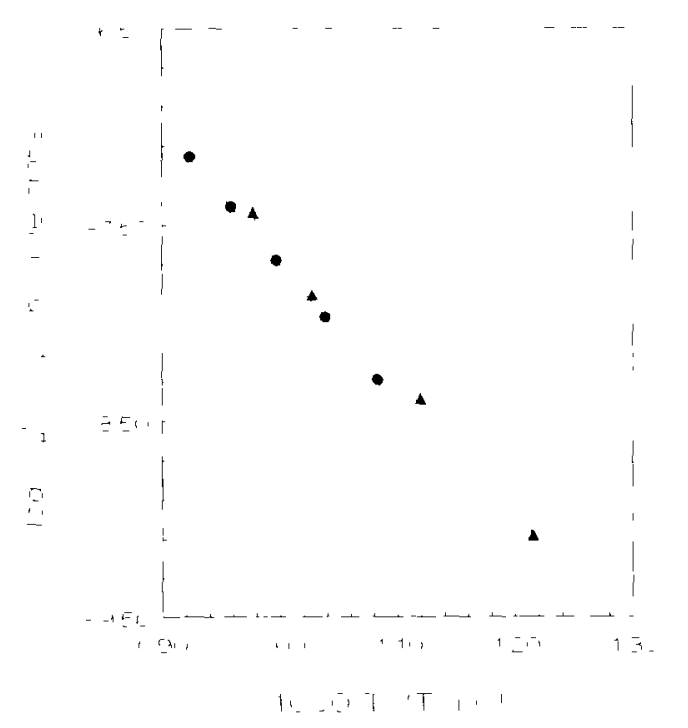

Fig 9 Comparison of the temperature dependence of the surface exchange rate, $J_{\mathrm{ex}}^{0}$, obtained from this study $(\bullet)$ (normalized to atr) and from oxygen isotope exchange ( $\Delta)$ reported by ref [14] fluence the rate determınıng step in the overall surface exchange reaction. For $\mathrm{B}_{2} \mathrm{O}_{4}$-based oxide electrolytes good agreement was obtained between the values obtained from both methods, indicating that the dissociative adsorption of oxygen occurs predominantly on the electrolyte surface [14.24] SIMS measurement revealed a rather flat diffusion profile. confirming that the surface reaction is ratedetermining in overall oxygen exchange.

It should be noted that high oxygen fluxes through ceramic membranes can only be sustained if the value of the surface exchange rate, $J_{\mathrm{ex}}^{\prime \prime}$, is also very high. Although the importance of the surface oxygen exchange reaction has been recognized by a number of authors [18.21.25-27], to date its understanding is stıll incomplete. In addition, it is believed that its role in determining the overall transport kinetics of mixed conducting oxides is overlooked in many theoretical studies [28-30].

If extrapolation to ultra-thın membranes is legitimate [31]. the maximum obtanable oxygen flux through BE25 according to the model description presented in section 4.2 is evaluated to be of the order of $\frac{1}{2} J_{\mathrm{ex}}^{(1)}$, where the prime refers to the high pressure side. The characteristic thickness at which diffusion and surface processes determine about equally the rate of oxygen permeation, for $P_{i_{2}}=1 \mathrm{~atm}$ (high pressure side). is calculated to be about $16 \times 10^{-2}$ $\mathrm{cm}$ at $650^{\circ} \mathrm{C}$ and $9 \times 10^{-2} \mathrm{~cm}$ at $810^{\circ} \mathrm{C}$, the values increasing with decreasing oxygen pressure. The corresponding value for calcia-stabılızed zirconia was found to be $27 \times 10^{-2} \mathrm{~cm}$ at $1230=\mathrm{C}[17]$. It should be emphasized that the derived values may be specific to the particular sample under investigation and may be affected by, for example, the preparation technique.

\section{EMH measurements}

In spite of an ionic transference number close to unity. EMF measurements indicate serious deviations from theoretical Nernst voltage. As is obvious from figs. 10 and 11, the deviation from ideal Nernst behaviour is not related to the extent of the permeating flux, which increases with temperature, but depend on the extent to which the rate is determined by surface oxygen exchange. A full discussion of the results of EMF measurements will be presented else- 


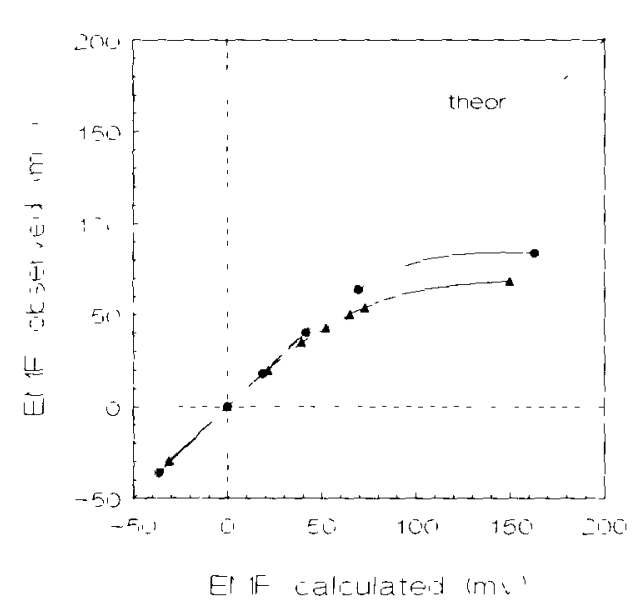

Fig 10 Companison of the EMF's of the cell Au,arr/BE25/ $/ P_{2}, A u$ at $650(\Delta)$ and $810^{\circ} \mathrm{C}(\bullet)$ with the theoretical Nernst voltage The electrolyte thickness is $0285 \mathrm{~cm}$

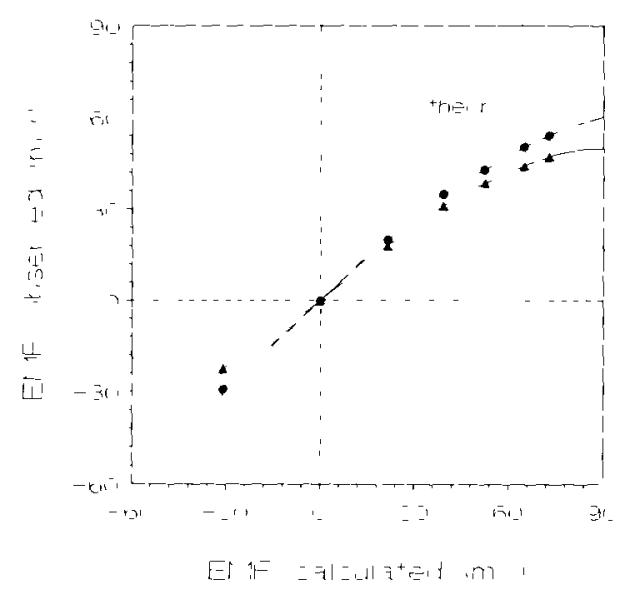

Fig 11 Comparison of the EMF's of the cell $\mathrm{Au}$,arr $/ \mathrm{BE} 25 / P_{\mathrm{O}_{2}}, \mathrm{Au}$ at $650^{\circ} \mathrm{C}$ with the theoretical Nernst voltage The electrolyte thickness is $0070(\Delta)$ and $0285 \mathrm{~cm}(\bullet)$, respectively

where [32]. Clearly these observations indicate severe limitations on the usefulness of the Nernst method for the determination of ionic and electronıc transference numbers in oxide electrolytes and mixed oxide conductors

\section{Conclusions}

Data have been provided which show that the rate of oxygen permeation through BE25 at steady-state is limited partly by solid state diffusion of electron holes and partly by the surface reaction. The degree of surface control depends on the environmental conditions, 1.e., oxygen pressure and temperature, as well as on specimen thickness. On assuming that bulk diffusion is of order $1 / 4$ and the surface reaction of order $5 / 8$ the partial $p$-type conductivity and the surface oxygen exchange rate have been calculated. The derived values for the surface exchange rate have been compared with avallable data measured using gas phase ${ }^{18} \mathrm{O}$ exchange. The good agreement noted supports the zonal approximation of steady-state oxygen permeation applied in this study. It is demonstrated that oxygen semipermeability of BE25 is directly correlated with the non-Nernstian behavlour of a galvanic cell incorporating BE25 as the solid electrolyte.

\section{References}

[1] F A Kroger and H J VInk, Solıd State Phys 3 (1956) 307

[2] L Heyne in Solıd Electrolytes. Topics in Applied Physics, ed S Geller (Sprnnger, Berlın. Heıdelberg, New York, 1977) p 169

[3] K W Browal and R H Doremus, J Am Ceram Soc 60 (1977) 262

[4] B Cales and J F Baumard, High Temp -High Pressures 14 (1982) 681

[5] R D 1 Cosimo, J D Burrington and R K Grasselli, J Catal $102(1986) 234$

[6] M Kleitz and E Siebert in Chemical Sensor Technology. Vol 2, ed T Seymana (Elsevier Amsterdam, 1989) p 151

[7]W C Maskell and B C H. Steele, J Appl Electrochem 59 (1986) 1997

[8] M J Verkerk, $K$ Keızer and A J Burggraaf, J Appl Electrochem $10(1980) 81$

[9] H Kruidhof, K Seshan, B C Lippens Jr . P.J Gellıngs and A J Burggraaf, Mat Res Bull 22 (1987) 1635

[10] H Kruldhof, K Seshan, G M H van de Velde. K.J de Vries and A J Burggraaf, Mat Res Bull 23 (1988) 371

[11] I C Vinke. K Seshan, BA Boukamp, $K J$ de Vries and A.J Burggraaf, Solıd State lonıcs 34 (1989) 235.

[12] I C Vinke, J L Bakiewicz. B A Boukamp, K J de Vries and A J Burggraaf Solid State lonics 40/41 (1990) 886

[13] B A Boukamp, K J de Vries and A.J Burggraaf in NonStorchıometric Compounds Surfaces, Grain Boundaries and Structural Defects, eds. J Nowotny and W Weppner (Kluwer, Dordrecht, 1989) p 299

[14] B A Boukamp, I C Vinke, K.J de Vries and A J Burggraaf, Solid State Ionies 32/33 (1989) 918 
[15] H Kruidhof, H J M Bounmeester, K J de Vrles, P J Gellings and A J Burggraaf, Solıd State lonics 50 (1992) 181

[16] J Fouletier, P Fabry and M Kleıtz, J Electrochem Soc 123 (1976) 204

[17] S Dou. C R Masson and P D Pacey.J Electrochem Soc $132(1985) 1843$

[18] J Nowotny and J B Wagner, Jr, Oxidat Met 15 (1981) 169

[19]A Brooke. D Kendrick and A Meeraus. GAMS (The Scientific Press. Redwood (1ty, 1988)

[20] K L Kliewer and J S Koehler, Phys Rev 140 (1965) 12264

[21] P J Gellings and $\mathrm{H} \mathrm{J} \mathrm{M} \mathrm{Bouwmeester,} \mathrm{Catal} \mathrm{Today} 12$ (1992) 1

[22] T Takahashı, $T$ Esaka and $H$ Iwahara J Appl Electrochem 7 (1977) 303

[23] E Kh Kurumchın and M V Perfillev, Solid State Ionics 42 (1990) 129

[24] B C H Steele, J A Kilner, P F Dennis, A E McHale, M van Hemert and $\mathrm{A} J$ Burggraaf, Solıd State lonıcs $18 / 19$ (1986) 1038
[25] B C H Steele, Mat Scı Eng B 13 (1992) 79

[26] P E Childs and J Wagner Jr, Heterogeneous Kinetics dt Elevated Temperatures (Plenum Press. New York, 1970) p 269

[27] A J Burggraaf, H J M Bouwmeester, B A Boukamp, R I R Uhlhorn and $V$ Zaspalis, in The Science of Ceramic Interfaces, ed J Nowotny (Elsevier, Amsterdam, 1991) p 525

[28] D S Tannhauser J Electrochem Soc $125(1978) 1277$

[29] I Riess. J Electrochem Soc 128 (1981) 2077

[30] T A Ramanarayanan, S Ling and M P Anderson. Proc Second Int Symp Solıd Oxide Fuel Cells (Athens, Greece 1991) p 777

[31] A J Burggraaf. B A Boukamp. H J M Bouwmeester, P J Gellıngs and $H$ Kruidhof, presented at 8 th Int Conf Solıd State lonics, October 20-26, 1991, Lake Louise, Canada

[32] H I M Bouwmeester. $H$ Kruidhof, P J Gellings and A J Burggraaf, to be published 